\title{
Pneumoretroperitoneum and Sepsis After Transanal Endoscopic Resection of a Rectal Lateral Spreading Tumor
}

\author{
Bruno Augusto Alves Martins, Marcelo de Melo Andrade Coura ${ }^{1}$, Romulo Medeiros de Almeida, \\ Natascha Mourão Moreira, João Batista de Sousa, Paulo Gonçalves de Oliveira \\ Division of Colorectal Surgery, School of Medicine, University of Brasília, Brasília; ${ }^{1}$ Department of Coloproctology, Uniprocto e Gastro \\ Clínica, Brasília, Brazil
}

Transanal endoscopic microsurgery is considered a safe, appropriate, and minimally invasive approach, and complications after endoscopic microsurgery are rare. We report a case of sepsis and pneumoretroperitoneum after resection of a rectal lateral spreading tumor. The patient presented with rectal mucous discharge. Colonoscopy revealed a rectal lateral spreading tumor. The patient underwent an endoscopic transanal resection of the lesion. He presented with sepsis of the abdominal focus, and imaging tests revealed pneumoretroperitoneum. A new surgical intervention was performed with a loop colostomy. Despite the existence of other reports on pneumoretroperitoneum after transanal endoscopic microsurgery, what draws attention to this case is the association with sepsis.

Keywords: Transanal endoscopic microsurgery; Retropneumoperitoneum; Sepsis

\section{INTRODUCTION}

The fundamentals of transanal endoscopic microsurgery (TEM) were established by Buess et al. in 1984 [1]. Since then, several modifications have been made to the equipment used. However, the concept of improving both the visibility and the reach of transanal surgery through improved optical techniques and through rectal distension obtained by using carbon dioxide has been maintained [2]. The TEM technique, which was initially conceived to facilitate the removal of sessile, unresectable rectal polyps by colonoscopy [3], gained strength in the local treatment of early rectal adenocarcinomas and is increasingly being applied in the advanced treatment of rectal cancer, such as the transabdominal-transanal proctosigmoidectomy, the total transanal mesorectal excision, and local approaches after neoadjuvant therapy.

Received: September 24, 2016 - Accepted: February 19, 2017

Correspondence to: Bruno Augusto Alves Martins, M.D.

Division of Colorectal Surgery, School of Medicine, University of Brasilia,

Brasilia, UnB 604/605 - Asa Norte, Brasilia, DF 70840-901, Brazil

Tel: +55-61-98188-3862, Fax: +55-61-3361-2100

E-mail: brunomartins.coloprocto@gmail.com

(C) 2017 The Korean Society of Coloproctology

This is an open-access article distributed under the terms of the Creative Commons Attribution NonCommercial License (http://creativecommons.org/licenses/by-nc/4.0) which permits unrestricted noncommercial use, distribution, and reproduction in any medium, provided the original work is properly cited.
TEM is considered a safe, appropriate, minimally invasive approach to the treatment of adenomas and early carcinomas of the rectum [4]. The primary objective of this study is to describe a case of pneumoretroperitoneum and sepsis in a patient who underwent a transanal resection of rectal tumor. The secondary objective is to present a literature review on complications associated with TEM. The patient whose case is presented here was properly informed and gave written informed consent for his clinical information and accompanying images to be included in this publication.

\section{CASE REPORT}

A 38-year-old male reported rectal mucous discharge for approximately 2 years without rectal bleeding or altered bowel habits. The patient was healthy, and he reported a family history of pancreatic cancer in a first-degree relative. Colonoscopy showed a nodularmixed type, lateral spreading tumor in the lower rectum, measuring $40 \mathrm{~mm}$ in its greatest diameter (Fig. 1). Histopathology showed a tubular-villous adenoma with high-grade dysplasia. Endorectal ultrasound with 3-dimensional reconstruction showed a mixed echogenicity image, staged as uTisN0, on the posterior wall of the rectum and located approximately $4.0 \mathrm{~cm}$ from the anal verge (Fig. 2).

The patient underwent an endoscopic transanal resection of the 


\section{$\begin{aligned} & \text { Coloproctology of } \text { Tumor } \\ & \text { Cruno Augusto Alves Martins, et al. }\end{aligned}$}

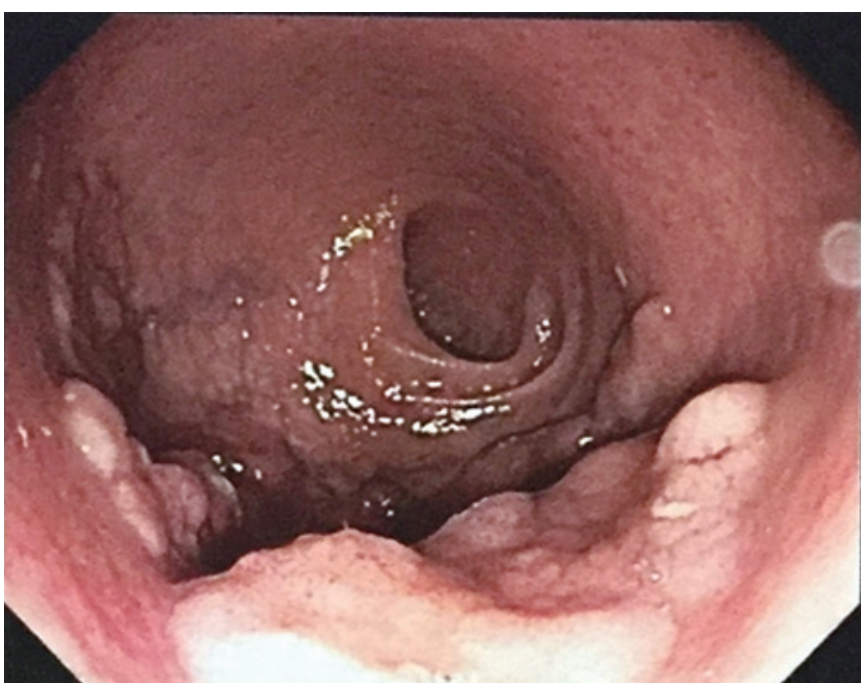

Fig. 1. Endoscopic view of the rectal lateral spreading, nodular-mixed type tumor.

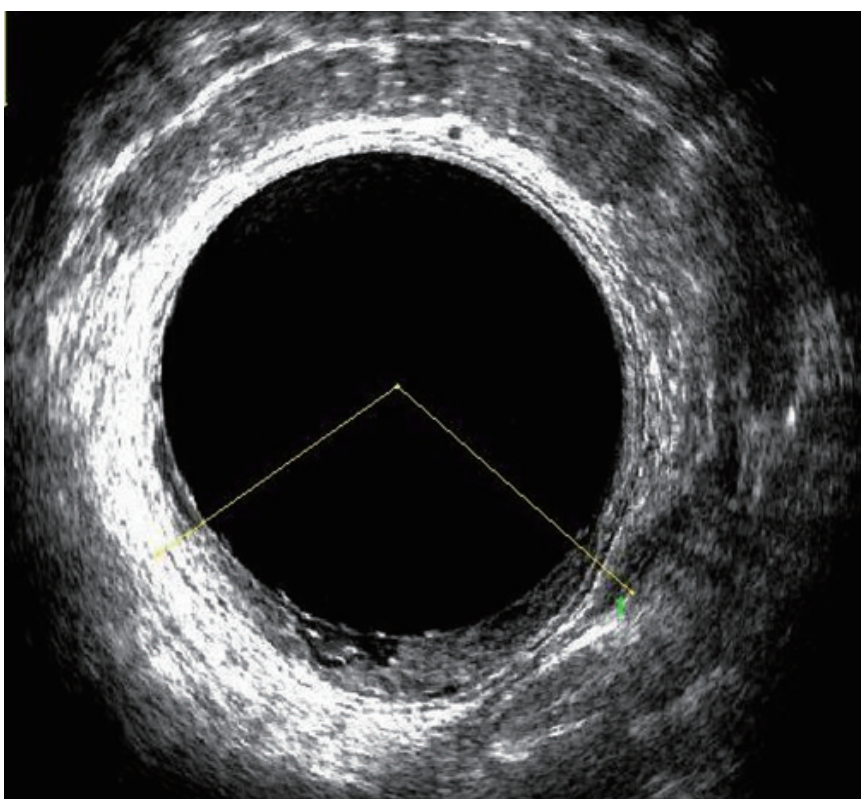

Fig. 2. Endorectal ultrasound image showing mixed echogenicity in a cross section of the lower rectum.

lesion, in total wall thickness, without complications. No rectal perforation into the peritoneal cavity was observed, and the wound in the rectal wall was closed by using a running suture with V-Loc (Covidien, Minneapolis, MN, USA). A transanal endoscopic operation system (TEO, Karl Storz GmbH, Tuttlingen, Germany) was used to perform the procedure. Colon mechanical preparation with mannitol and extended surgical antibiotic prophylaxis with ciprofloxacin (400 mg intravenous $12 \times 12$ hours) and metronidazole (500 $\mathrm{mg}$ intravenous $8 \times 8$ hours) were per-

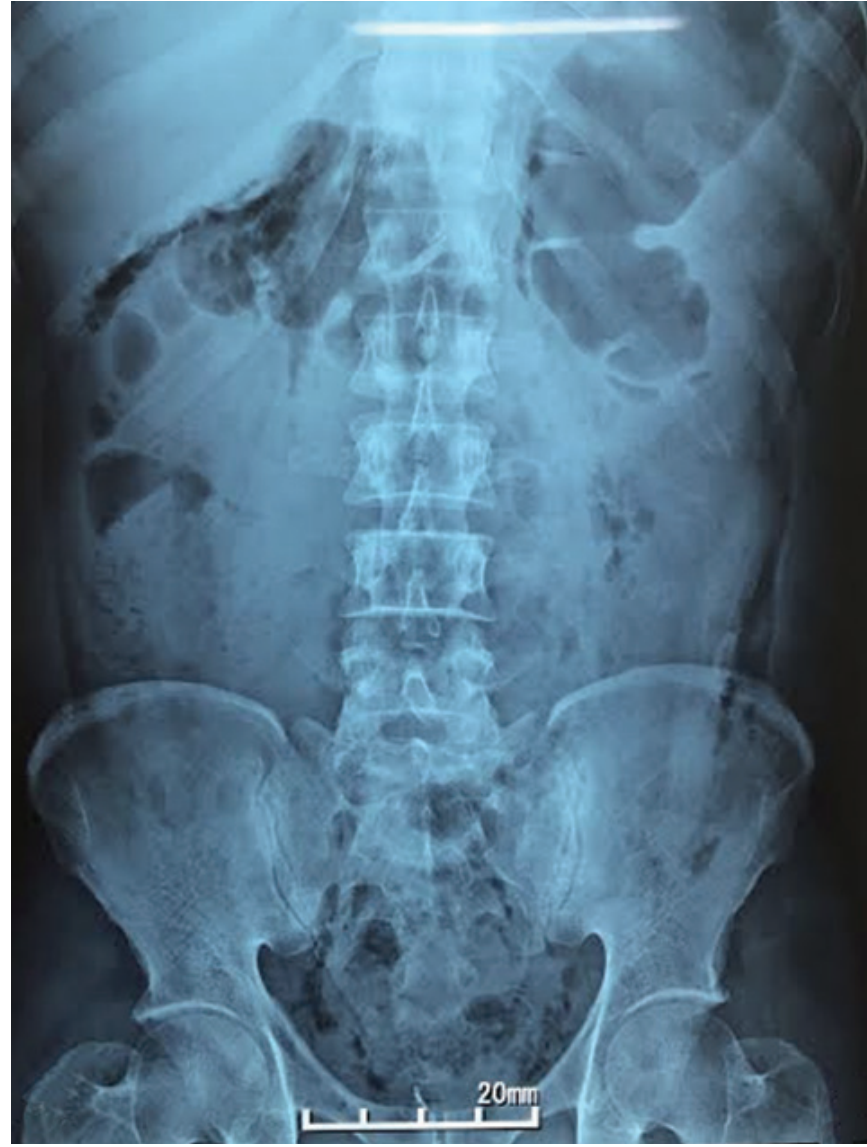

Fig. 3. Abdominal radiography showing pneumoretroperitoneum.

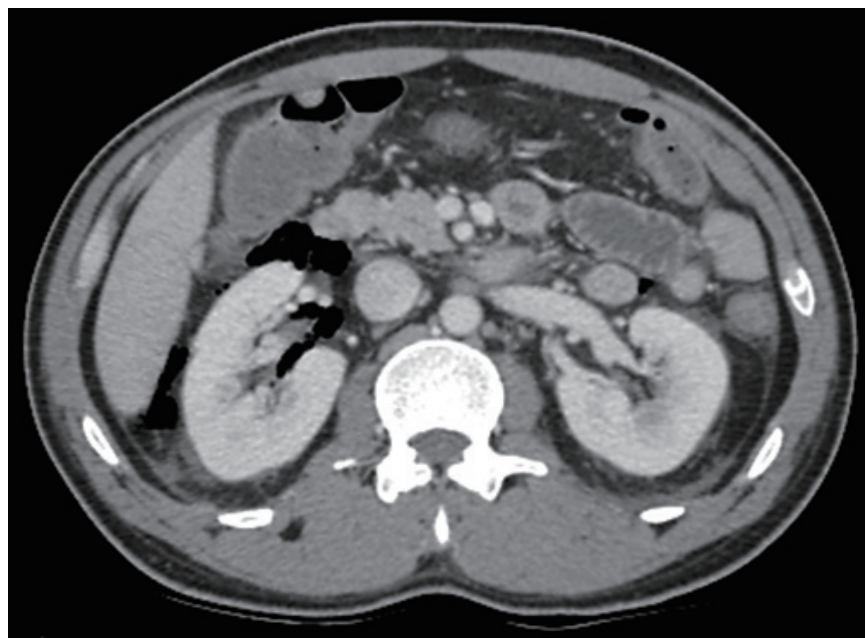

Fig. 4. Abdominal computed tomography scan showing retroperitoneal air surrounding the right kidney.

formed. The resected lesion was histologically analyzed, and the results proved the existence of a tubular-villous adenoma with high-grade dysplasia and a focus of an intramucosal carcinoma. 
Surgical margins were negative.

One day after surgery, no abdominal discomfort or nausea was present, the patient had no fever, and solid food was tolerated. On the second postoperative day, the patient developed diffuse abdominal pain and asthenia. Physical examination revealed a heart rate of 122 beats $/ \mathrm{min}$, a respiratory rate of 25 breaths $/ \mathrm{min}$, and a painful abdomen to deep palpation. Laboratory tests revealed a white blood cell count of $10,270 / \mathrm{mm}^{3}$ with $14 \%$ immature forms, a serum C-reactive protein level of $25 \mathrm{mg} / \mathrm{dL}$, metabolic acidosis, and elevated lactic acid. In accordance with the diagnosis of an abdominal focus of sepsis, volume expansion was initiated, antibiotics were changed to piperacillin-tazobactam $(4.0+0.5 \mathrm{~g}$ intravenous $12 \times 12$ hours), and the patient was admitted to the intensive care unit.

Abdominal radiography and computed tomography of the abdomen with intravenous contrast revealed pneumoretroperitoneum (Figs. 3, 4). The patient underwent a laparotomy. Diffuse retroperitoneal gas infiltration was observed. A loop colostomy and opening of the points of the rectal wound were performed. The patient remained hospitalized in the intensive care unit for five days, and was discharged in good general condition 11 days after the first surgical approach. After 6 months, the stoma was closed without complications.

\section{DISCUSSION}

Postoperative complications are rare after TEM [5]. Bretagnol et al. [6] reported on a series of 200 patients undergoing TEM and found a 30 -day mortality of $0.5 \%$ and morbidity of $14 \%$. In a series of 425 patients with rectal cancer treated by using TEM, Guerrieri et al. [7] showed no perioperative mortality and no intraoperative complications. Regarding postoperative complications, the minor complication (suture line dehiscence, bleeding and fecal incontinence) rate was $9.9 \%$, and the major complication (2 urethral injuries, a perianal abscess, a rectovaginal fistula, and 2 retroperitoneal phlegmons) rate was $1.4 \%$. The retroperitoneal phlegmons were treated by drainage and diversion of intestinal transit.

Pneumoretroperitoneum is described as a complication of colorectal endoscopic procedures, especially endoscopic submucosal dissections [8-10]. Insufflation with carbon dioxide, instead of ambient air, can prevent this complication because Carbon dioxide is more rapidly absorbed and eliminated by the body [10, 11]. In the case of TEM, the use of carbon dioxide insufflation to prevent the formation of pneumorectum is standard, and pneumoretroperitoneum is rarely reported as a complication in this procedure. Simkens et al. [5] described a case of massive retroperitoneal emphysema and subcutaneous emphysema after TEM for the resection of an intramucosal rectal carcinoma, but without signs of sepsis. Cantos et al. [12] also described a case involving the presence of subcutaneous emphysema and pneumomediastinum after an adenoma resection by using TEM.
Despite the existence of other reports on pneumoretroperitoneum after TEM, what draws attention to this case is the association with sepsis. With increased application of transanal endoscopic approaches more unusual complications, which will require long-term analysis to establish methods for reducing morbidity, are expected to occur and will need to be described.

\section{CONFLICT OF INTEREST}

No potential conflict of interest relevant to this article was reported.

\section{REFERENCES}

1. Buess G, Theiss R, Gunther M, Hutterer F, Hepp M, Pichlmaier H. Endoscopic operative procedure for the removal of rectal polyps. Coloproctology 1984;6:254-61.

2. Saclarides TJ. Transanal endoscopic microsurgery. Clin Colon Rectal Surg 2015;28:165-75.

3. Heidary B, Phang TP, Raval MJ, Brown CJ. Transanal endoscopic microsurgery: a review. Can J Surg 2014;57:127-38.

4. Palma P, Horisberger K, Joos A, Rothenhoefer S, Willeke F, Post S. Local excision of early rectal cancer: is transanal endoscopic microsurgery an alternative to radical surgery? Rev Esp Enferm Dig 2009;101:172-8.

5. Simkens GA, Nienhuijs SW, Luyer MD, de Hingh IH. Massive surgical emphysema following transanal endoscopic microsurgery. World J Gastrointest Surg 2014;6:160-3.

6. Bretagnol F, Merrie A, George B, Warren BF, Mortensen NJ. Local excision of rectal tumours by transanal endoscopic microsurgery. Br J Surg 2007;94:627-33.

7. Guerrieri M, Gesuita R, Ghiselli R, Lezoche G, Budassi A, Baldarelli M. Treatment of rectal cancer by transanal endoscopic microsurgery: experience with 425 patients. World J Gastroenterol 2014;20:9556-63.

8. Sato K, Itoh S, Shigiyama F, Kitagawa T, Maetani I. Pneumoretroperitoneum, pneumomediastinum andsubcutaneous emphysema after colorectal endoscopic submucosal dissection (ESD) with air insuflation. J Interv Gastroenterol 2011;1:136-8.

9. Park NS, Choi JH, Lee DH, Kim YJ, Kim ES, Jung SW, et al. Pneumoretroperitoneum, pneumomediastinum, peumopericardium, and subcutaneous emphysema after colonoscopic examination. Gut Liver 2007;1:79-81.

10. Meyer MM, Cruz GM, Sampaio, DV, De Lanna D, Costa LM, Teixeira RG, et al. Pneumoretroperitoneum, pneumomediastinum and subcutaneous emphysema after endoscopic submucosal dissection of a rectal lateral spreading tumor. J Coloproctol (Rio J) 2014;34:265-8.

11. Saito Y, Uraoka T, Matsuda T, Emura F, Ikehara H, Mashimo Y, et al. A pilot study to assess the safety and efficacy of carbon dioxide insufflation during colorectal endoscopic submucosal dissection with the patient under conscious sedation. Gastrointest Endosc 


\section{Coloproctology Bruno Augusto Alves Martins, et al.}

2007;65:537-42.

12. Cantos M, Bruna M, García-Coret MJ, Villalba FL, Roig JV. Pneumomediastinum and subcutaneous emphysema like strange com- plications after transanal endoscopic microsurgery. Rev Esp Enferm Dig 2009;101:445-6. 